\title{
Pemberdayaan Masyarakat Desa Dalam Pembangunan Desa Wisata Melalui Metode Serap Aspirasi Masyarakat
}

\author{
Husein Abdurahman ${ }^{1}$, Sarwani ${ }^{2}$, Angga Ardiyanto ${ }^{3}$, Budi Rahman $_{7}^{4}$ Miftahul Jannah $^{5}$, \\ Nur Laeliana ${ }^{6}$, Rinaldi Juliansyah ${ }^{7}$, Rizky Annisa ${ }^{8}$ \\ ${ }^{1,2}$ Universitas Lambung Mangkurat, Fakultas Ilmu Sosial dan Ilmu Politik, \\ Jl. H. Hasan Basry, Banjarmasin, Indonesia, \\ 3,4,5,6,7,8 Mahasiswa Program Studi Ilmu Pemerintahan, Universitas Lambung Mangkurat,
. \\ Fakultas Ilmu Sosial dan Ilmu Politik, \\ Jl. H. Hassan Basry, Banjarmasin, Indonesia, \\ *email korespondensi: huseinabdurrahman.fisip@ulm.ac.id
}

Diajukan

29 Oktober 2021
Informasi Artikel

Diterima

20 November 2021
Diterbitkan

30 November 2021

\section{Keywords:}

Komunitas

Desa wisata

Desa Sungai Langsat

Serap aspirasi masyarakat

Pengabdian Masyarakat

\begin{abstract}
Sungai Langsat Village has beautiful natural conditions and has tourist attraction and potential which if developed provides opportunities for this village to become a tourist village. The methodology used in carrying out this aspiration absorption activity is the Participatory Rural Appraisal (PRA) method. The result of this program is that the people of Sungai Langsat village, who initially did not know what a tourist village was, became aware of it and the response given by the village community regarding building a tourist village was also quite good. It is hoped that the village government can increase the participation of the village community based on the results of the study conducted, and for the community it is hoped that it will be more active in participating in village development, especially in village tourism planning which at the same time moves and grows the economy of rural communities.
\end{abstract}

\section{ABSTRAK}

Desa Sungai Langsat memiliki kondisi alam yang asri dan memiliki daya tarik dan potensi wisata yang jika dikembangkan memberikan peluang bagi desa ini untuk menjadi desa wisata. Untuk meningkatkan keberdayaan masyarakat, kegiatan serap aspirasi masyarakat dilakukan yaitu mengumpulkan, menampung dan menyalurkan aspirasi masyarakat terkait rencana pengembangan desa wisata. Metodologi yang digunakan dalam melaksanakan kegiatan serap aspirasi ini adalah metode Participatory Rural Apraisal (PRA). Hasil dari program ini diketahui bahwa masyarakat desa Sungai Langsat yang awalnya tidak tahu apa itu desa wisata menjadi tahu dan respon yang diberikan masyarakat desa terkait membangun desa wisata juga cukup baik. Diharapkan pemerintah desa dapat meningkatkan partisipasi masyarakat desa berdasarkan hasil studi yang dilakukan, dan untuk masyarakat diharapkan lebih aktif dalam partisipasi pembangunan desa khususnya dalam perencanaan desa wisata yang mana sekaligus menggerakkan dan menumbuhkan perekonomian masyarakat pedesaan.

\section{Copyright and License:}

Authors retain copyright and grant the journal right of first publication with the work simultaneously licensed under a Creative Commons Attribution 4.0 International License that allows others to share the work with an acknowledgment of the work's authorship and initial publication in this journal. 


\section{PENDAHULUAN}

Desa wisata kini menjadi sebuah trend dalam pembangunan desa melalui sektor pariwisata. Desa wisata merupakan salah satu program Pemerintah Republik Indonesia terhadap pengembangan pariwisata berkelanjutan yang diharapkan dapat mempercepat kemajuan pariwisata dan memicu pertumbuhan ekonomi masyarakat desa. Program desa wisata secara sederhana bertujuan untuk memberdayakan mayarakat desa dengan motivasi untuk membangun, mengelola secara kreatif terhadap potensi alam dan budaya yang ada sehingga mampu meningkatkan aktivitas ekonomi masyarakat desa.

Pembangunan desa wisata (objek wisata) dengan memanfaatkan potensi alam dan budaya yang ada di desa serta memperhatikan komponen-komponen dalam membentuk desa wisata tentunya dibutuhkan partisipasi, kerjasama dan konsistensi dari seluruh elemen terkait, khususnya pemerintah desa bersama masyarakat desa. Tanpa adanya ketiga unsur tersebut akan terjadi suatu hambatan dalam merealisasikan desa wisata. Permasalahan inilah yang terjadi di Desa Sungai Langsat Kabupaten Banjar, Kalimantan Selatan.

Desa Sungai Langsat merupakan salah satu desa di Kecamatan Simpang Empat, Kabupaten Banjar. Secara umum keadaan topografi Desa Sungai Langsat berupa lereng dan puncak yang sebagian besar lahannya merupakan wilayah perkebunan (Gambar 1). Desa Sungai Langsat memiliki kondisi alam yang asri dan memiliki daya tarik dan potensi wisata yang jika dikembangkan memberikan peluang bagi desa ini untuk menjadi desa wisata (Gambar 2 \& Gambar 3). Potensi tersebut diantaranya kawasan perkebunan, pertanian, puncak dan danau. Walaupun terdapat berbagai potensi pariwisata ini di Desa Sungai Langsat, tetapi masih belum ada pengelolaan dan perealisasian dalam menjadikanya sebagai sebuah objek wisata yang mengarah ke pembangunan desa wisata. Arus urbanisasi masyarakat Desa Sungai Langsat yang tinggi juga menjadi sebuah kekhawatiran terhadap perkembangan dan kemajuan desa. Ditambah lagi partisipasi masyarakat yang tergolong pasif dari segi partisipasi untuk membangun desa. Oleh karena itu, Pemerintah Desa Sungai Langsat memiliki pra-perencanaan untuk membangun suatu objek wisata dengan harapan dapat menjadi langkah awal bagi Desa Sungai Langsat untuk menjadi sebuah desa wisata.

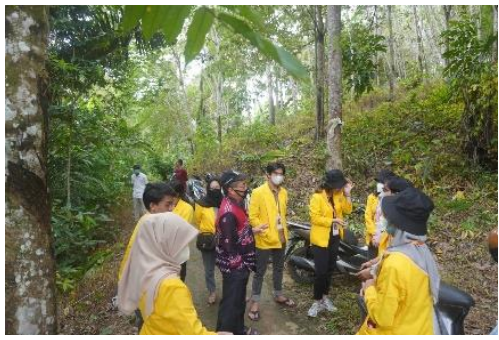

(1)

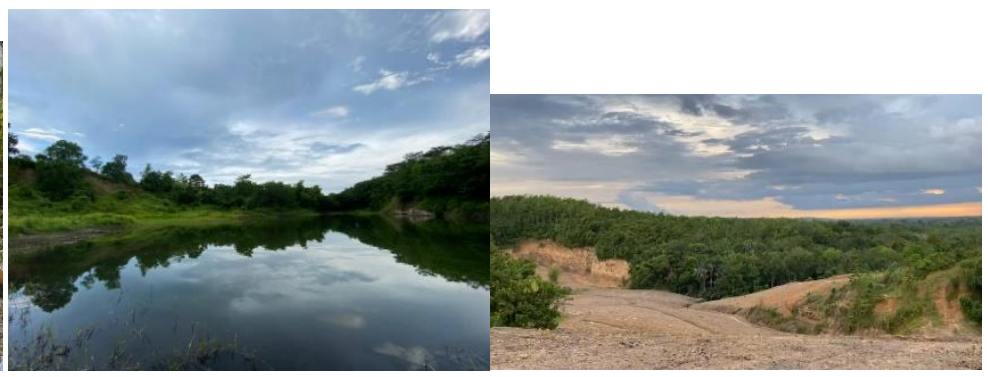

(2)
(3)

Sumber : Hasil Dokumentasi, 2021.

Adanya pra-perencanaan pemerintah desa dalam membangun objek wisata dengan memanfaatkan potensi wisata yang ada di Desa Sungai Langsat dan sesuai dengan Peraturan Menteri Pariwisata Republik Indonesia Nomor 29 Tahun 2015 dengan pengembangan wisata berbasis pedesaan (desa wisata) diharapkan akan memicu aktivitas ekonomi di desa sehingga akan mencegah terjadinya urbanisasi masyarakat Desa Sungai Langsat.

Untuk itu, keberdayaan masyarakat desa perlu ditingkatkan dalam pembangunan desa wisata melalui metode serap aspirasi masyarakat. Selanjutnya, perlu diadakan pengabdian dengan judul "Pemberdayaan Masyarakat Desa dalam Pembangunan Desa Wisata melalui Metode Serap Aspirasi Masyarakat". Dari kegiatan tersebut diharapkan pemerintah desa mampu meningkatkan partisipasi masyarakat berdasarkan hasil aspirasi yang dihimpun, sehingga masyarakat dapat menjadi lebih aktif dalam berpartisipasi membangun desa khususnya dalam perencanaan pengembangan objek wisata di Desa Sungai Langsat.

\section{METODE}

Serap Aspirasi adalah suatu kegiatan yang menjadi sarana untuk mengumpulkan dan menampung pendapat, pemikiran, usulan, maupun keinginan dari suatu objek sasaran yang telah ditentukan. Kegiatan "Pemberdayaan Masyarakat Desa dalam Pembangunan Desa Wisata melalui Metode Serap Aspirasi Masyarakat" dilakukan oleh Mahasiwa Kelompok 12 KKN FISIP ULM secara door to door atau dari 
rumah ke rumah karena dalam kondisi Pandemi Covid-19 saat ini dengan tujuan untuk tidak mengadakan kerumunan.

Metodologi yang digunakan dalam melaksanakan kegiatan serap aspirasi ini adalah metode Participatory Rural Apraisal (PRA) dimana para warga diajak melakukan analisa terkait pra-perencanaan desa wisata di desanya. Mahasiswa Kelompok 12 KKN FISIP ULM menyusun sebuah pedoman wawancara berdasarkan metode PRA dengan tujuan untuk memberdayakan masyarakat desa dalam kegiatan membangun desa dimasa yang akan datang. Aspirasi yang terkumpul ini nantinya akan menjadi bahan masukan bagi Pemerintah Desa Sungai Langsat dalam memberdayakan sekaligus meningkatkan partisipasi masyarakat desa dalam kegiatan-kegiatan membangun desa, khsusnya dalam rencanaan pembangunan desa wisata.

\section{HASIL DAN PEMBAHASAN}

Pengabdian yang dilakukan adalah Serap Aspirasi Masyarakat Desa mengenai pra-perencanaan untuk menjadikan Desa Sungai Langsat menjadi desa wisata. Mahasiswa Kelompok 12 KKN FISIP ULM melakukan wawancara dari rumah ke rumah menggunakan instrumen pedoman wawancara yang telah disusun berdasarkan metode Participatory Rural Apraisal (PRA) dan juga menyebarnya dalam bentuk kuesioner menggunakan media google form melalui aplikasi WhatsApp. Serap Aspirasi dilakukan pada warga Desa Sungai Langsat (Gambar 4 \& 5). Setelah aspirasi yang terkumpul disimpulkan maka selanjutnya akan disampaikan kepada pihak pemerintah desa sehingga dapat menjadi bahan pertimbangan dalam nemulai penyusunan rencana pembangunan desa wisata. Tahapan yang dilakukan pada kegiatan pengabdian sebagai berikut:

\section{Tahapan Persiapan}

Pada awal persiapan, Mahasiswa Kelompok 12 KKN FISIP ULM melakukan observasi desa. Pada tahap ini dilakukan wawancara dengan kepala desa untuk mengetahui gambaran keadaan desa khususnya keadaan sosial dan ekonomi masyarakat. Selain itu, kami berdiskusi dengan kepala desa mengenai tingkat partisipasi masyarakat Desa Sungai Langsat selama ini dalam kegiatan pembangunan yang diadakan oleh desa. Hal ini kami lakukan untuk menentukan dugaan awal dari penyebab kurangnya minat keikutsertaan warga dalam kegiatan pembangunan di Desa Sungai Langsat. Kemudian disimpulkan dugaan awal bahwa yang menjadi penyebab kepasifan warga adalah rasa kebingungan karena ketiadaan potensi wisata yang terlihat signifikan di desanya, dan hanya ada rencana pemerintah desa untuk membuat tempat pemancingan di danau bekas galian tambang yang ada di sana.

Selanjutnya kami menyusun poin-poin pertanyaan sebagai bahan acuan dalam melaksanakan kegiatan serap aspirasi. Daftar pertanyaan ini disusun berpedoman pada metode PRA agar menuntun masyarakat untuk ikut memikirkan masalah dan solusi terkait pra-perencanaan Pemerintah Desa Sungai Langsat dalam pebangunan desa wisata.

\section{Tahapan Pelaksanaan}

Pelaksanaan kegiatan serap aspirasi masyarakat dilakukan selama tiga hari berturut-turut. Kegiatan serap aspirasi masyarakat dalam rangka membangun desa wisata di Desa Sungai Langsat terlaksana dengan dukungan berbagai pihak, khususnya dari pihak pemerintah desa dan masyarakat Desa Sungai Langsat. Pada pelaksanaan kegiatan serap aspirasi ini terdapat beberapa tahap yaitu :

(1) Melakukan kunjungan ke masyarakat desa RT.1, RT.2 dan RT.3 dengan sistem door to door.

(2) Melakukan diskusi, wawancara dan serap aspirasi kepada masyarakat terkait rencana menjadikan desa sungai langsat sebagai desa wisata. Dalam kegiatan ini, sebagai pembuka

diskusi Mahasiswa Kelompok 12 KKN FISIP ULM menanyakan pengetahuan masyarakat tentang desa wisata. Selanjutnya dikenalkan tentang konsep desa wisata sesuai dengan Peraturan Menteri Pariwisata Republik Indonesia Nomor 29 Tahun 2015 tentang pengembangan wisata berbasis pedesaan atau disebut dengan desa wisata. Masyarakat diberikan pemahaman bahwa program desa wisata ini bertujuan untuk memberdayakan mayarakat desa dengan motivasi untuk membangun, mengelola secara kreatif terhadap potensi alam dan budaya yang ada sehingga mampu meningkatkan aktivitas ekonomi masyarakat desa. Kemudian mulailah dilakukan wawancara terkait permasalahan dan solusi warga terhadap pra-perencanaan Desa Sungai Langsat menjadi desa wisata. 


\section{Gambar 4 dan 5.}

Pemaparan dan wawancara tentang pra-perencanaan

Desa Sungai Langsat menjadi desa wisata

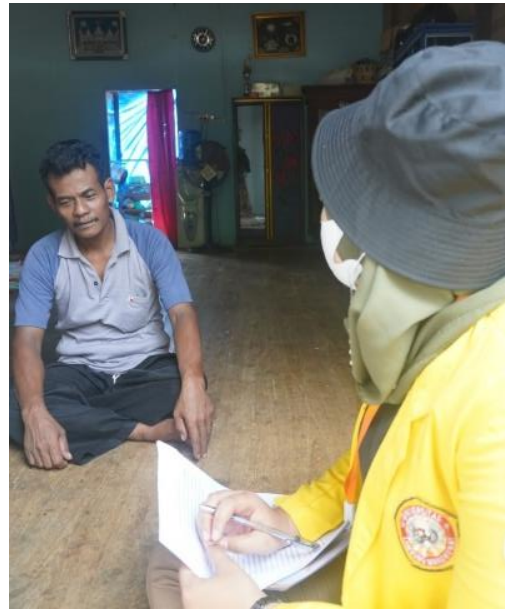

(4)

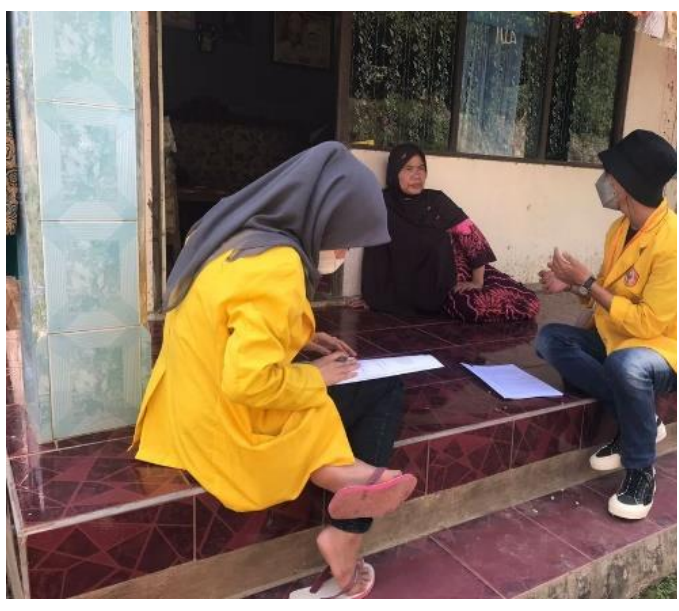

(5)

Sumber : Hasil Dokumentasi, 2021

(3) Mengolah dan menyimpulkan hasil serap aspirasi yang dilakukan secara sistematis untuk diserahkan kepada (Gambar 6).

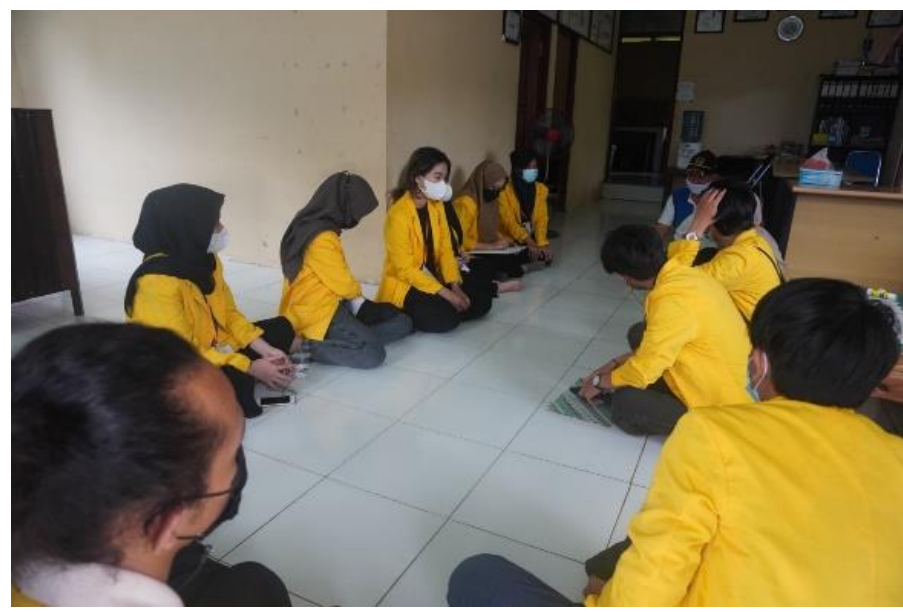
pemerintah desa

Sumber : Hasil Dokumentasi, 2021.

(4) Menyusun saran dan strategi pemberdayaan masyarakat desa dari aspek membangun objek wisata sekaligus menyerahkan hasil dari serap aspirasi masyarakat dalam membangun desa wisata kepada pemerintah desa untuk dijadikan sebagai bahan pertimbangan dan masukan bagi pemerintah desa dalam melakukan pemberdayaan masyarakat desa dengan harapan mampu meningkatkan partisipasi masyarakat desa. 
Gambar 7. Mahasiswa Kelompok 12 KKN FISIP ULM berkunjung ke Kantor Desa Sungai Langsat untuk menyerahkan simpulan hasil serap aspirasi yang telah dilaksanakan.

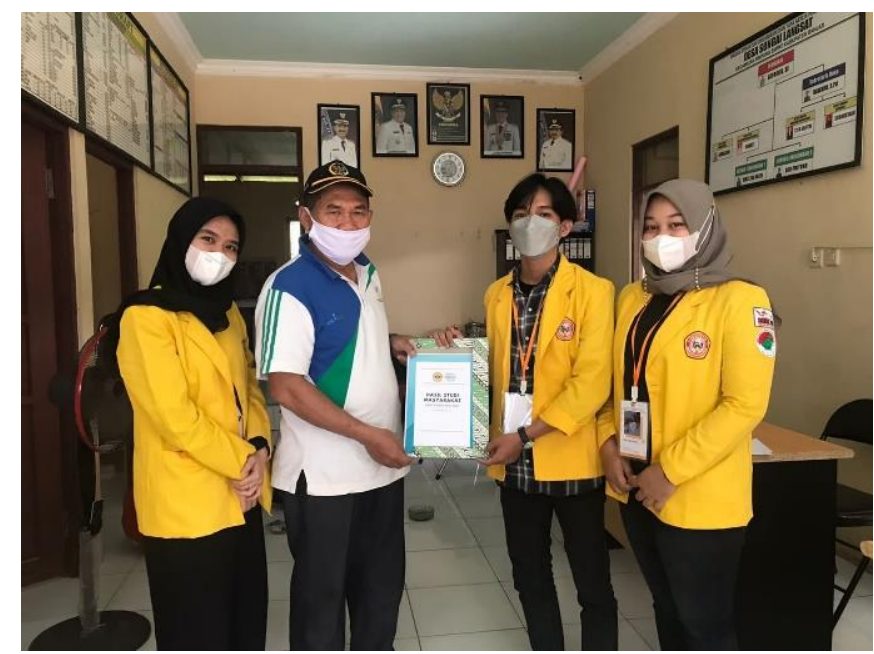

Sumber : Hasil Dokumentasi, 2021.

Hasil pelaksanaan kegiatan pengabdian selanjutnya secara garis besar dapat dilihat dari penilaian beberapa komponen berikut ini, antara lain:

1. Ketercapaian tujuan kegiatan serap aspirasi

Tujuan kegiatan serap aspirasi adalah memberikan masyarakat pengetahuan tentang desa wisata dan mengajak masyarakat untuk menyuarakan aspirasinya terkait pra-perencanaan pembangunan Desa Sungai Langsat menjadi desa wisata. Masyarakat didorong untuk ikut memikirkan potensi, masalah, dan keinginannya terhadap pembangunan desa wisata. Dalam pelaksanaan kegiatan serap aspirasi, materi wawancara yang disampaikan sesuai dengan tingkat pemahaman masyarakat agar mudah dimengerti mengingat sebagian besar masyarakat berprofesi sebagai petani dan pedagang. Jika dilihat dari ketercapaian tujuan kegiatan serap aspirasi dapat dinilai cukup baik, dalam hal ini ada peningkatan pengetahuan masyarakat tentang desa wisata dan wilayahnya yang berpotensi untuk dijadikan desa wisata serta masyarakat telah mampu mengutarakan kendala dan alternatif solusi untuk permasalahannya.

2. Ketercapaian target materi pertanyaan yang telah direncanakan

Materi pertanyaan yang telah direncanakan, antara lain mengenai keadaan koordinasi antar masyarakat dengan pemerintah desa, wawasan dan pendapat mengenai membangun desa wisata, pendapat masyarakat mengenai potensi wisata yang ada di desanya, dan pendapat masyarakat mengenai kinerja pemerintah desa khususnya di bidang penyerapan aspirasi warga. Semua materi pertanyaan telah disampaikan kepada masyarakat, sehingga diharapkan adanya pemahaman masyarakat akan desa wisata serta peningkatan partisipasi masyarakat desa.

3. Penerimaan masyarakat terhadap materi dalam wawancara yang dilakukan

Kemampuan masyarakat dalam memahami semua materi yang telah disampaikan dalam wawancara dapat dinilai cukup baik walaupun durasi wawancara setiap rumahnya hanya sekitar setengah jam. Untuk itu materi wawancara disampaikan dengan bahasa yang lugas, jelas, dan menggunakan contohcontoh yang mudah dimengerti. Hal ini dikarenakan tingkat pendidikan masyarakat yang beragam sehingga dikhawatirkan bagi warga yang memiliki tingkat pendidikan rendah akan kurang mampu menyerap materi.

\section{KESIMPULAN}

Pada kegiatan Serap aspirasi masyarakat ini, dapat diambil kesimpulan sebagai berikut :

(1) Desa Sungai langsat memiliki potensi wisata yang cukup baik apabila dikembangkan menjadi sebuah objek wisata ataupun menjadi sebuah desa wisata, khususnya dari bidang perkebunan dan wisata alam. 
(2) Tahap awal persiapan kegiatan serap aspirasi masyarakat berupa penyusunan pedoman wawancara untuk meningkatkan keberdayaan masyarakat dalam rangka membangun Desa Sungai Langsat menjadi sebuah desa wisata ini

(3) Tahap pelaksanaan kegiatan serap aspirasi ini menerima dukungan dari berbagai pihak, khususnya pemerintah desa dan masyarakat.

(4) Hasil dari kegiatan serap aspirasi masyarakat untuk membangun desa wisata ini menunjukan bahwa masih adanya masyarakat yang belum mengetahui apa itu desa wisata.

(5) Dari kegiatan serap aspirasi masyarakat untuk membangun desa wisata yang dilaksanakan didapati bahwa masyarakat cenderung mendukung rencana tersebut dengan catatan mendahulukan pembangunan desa yang lebih mendesak seperti perbaikan jalan dan jembatan.

\section{UCAPAN TERIMAKASIH}

Ucapan terimakasih atas terlaksananya kegiatan pengabdian ini dalam program serap aspirasi masyarakat di sampaikan kepada :

(1) Kepala Desa dan seluruh perangkat Desa Sungai Langsat

(2) Masyarakat Desa Sungai Langsat

(3) Seluruh pihak yang terlibat dan membantu terlaksananya kegiatan ini

\section{REFERENSI}

Zakaria, Faris dan Rima Dewi Suprihardjo. (2014). "Konsep Pengembangan Kawasan Desa Wisata di Desa Bandungan Kecamatan Pakong”. Jurnal Teknik Pomits. 3(2): 245-249. Diakses dari http://media.neliti.com/media/publications/194629-ID-konsep-pengembangan-kawasan-desa-wisata.pdf (17 September 2021)

Hudayana, Bambang dkk. (2019). "Participatory Rural Apprasial (PRA) untuk Pengembangan Desa Wisata di Pedukuhan Pucung, Desa Wukirsari, Bantul". Jurnal Bakti Budaya. 2(2): 99-112. Diakses dari https://journal.ugm.ac.id/bakti/article/download/50890/pdf (25 September 2021)

Yudha, Very. 2019. "Participatory Rural Appraisal Dalam Praktik Desa Wisata", https://www.desabisa.com/participatory-rural-appraisal-dalam-praktik-desa-wisata/ diakses pada 21 September 2021 pukul 20:20 WITA.

http://diparda.gianyarkab.go.id/index.php/en/news/item/304-pengembangan-desa-wisata (Diakses September 2021, pukul 13:34 WITA)

https://kemenparekraf.go.id/kebijakan/Desa-Wisata-Terus-Tumbuh-Sebagai-Pariwisata-Alternatif (Diakses 21 September 2021, pukul 20:35 WITA). 